\title{
VERDAD: UN ANÁLISIS LÓGICO-SEMÁNTICO
}

\author{
TRUTH: A LOGICAL-SEMANTIC ANALYSIS \\ José Andrés Forero Mora
}

\begin{abstract}
María José Frápolli (2013): The Nature of Truth. An updated approach to the meaning of truth ascriptions. Dordrecht: Springer.
\end{abstract}

El problema de la verdad es, sin duda, uno de los problemas filosóficos más antiguos. Ríos de tinta han sido derramados desde la antigüedad con el fin de comprender cuál es la naturaleza de este concepto y, en últimas, qué es aquello a lo que llamamos verdad. El siglo XX, y el desarrollo de la lógica y la filosofía del lenguaje que este trajo consigo, no opacó la preocupación filosófica por el concepto de verdad; por el contrario, dotó a los filósofos interesados con nuevas herramientas lógicas de análisis, lo cual contribuyó a que brotaran múltiples teorías lógico-semánticas de la verdad. El libro objeto de este comentario se ubica justamente en este tipo de análisis. En él la profesora Frápolli presenta lo que ha denominado una teoría prooracional ampliada de la verdad (enriched prosentential account of truth) que, junto con algunos desarrollos de la lingüística y de la filosofía del lenguaje contemporáneas, pretende «disipar el aire de misterio que tradicionalmente ha acompañado a esta noción», explicando cuál es el funcionamiento que el concepto de verdad tiene en los intercambios comunicativos.

Antes de examinar en qué consiste la teoría prooracional presentada por Frápolli, es necesario resaltar la actitud pragmatista y pragmática con que ella se enfrenta al problema de la verdad; es pragmatista en tanto encarna el espíritu del pragmatismo clásico (p. ej., Peirce, Ramsey) y pragmática en la medida en que se nutre de la tradición iniciada por el segundo Wittgenstein, Austin y Searle en filosofía del lenguaje ${ }^{1}$. De acuerdo con sus propias palabras, el

\footnotetext{
${ }^{1}$ La adopción de una actitud pragmatista no implica la adopción de una teoría pragmatista, en el sentido clásico del término, de la verdad.
} 
trasfondo pragmatista se refleja en su «compromiso con las prácticas racionales como el punto de partida del análisis filosófico, su rechazo de cualquier clase de escolasticismo [...] y su aceptación de que la realidad puede ser individualizada, explicada y analizada de diferentes maneras para propósitos teóricos diversos» (p. 16). Esta actitud pragmatista le permitirá a la autora posteriormente rechazar cualquier clase de compromiso ontológico con los conceptos y categorías propios de su teoría (p. ej., el de proposición), pues finalmente estos no son más que herramientas para comprender las prácticas racionales de los hablantes. La actitud pragmática, por su parte, se ve reflejada en el conjunto de su teoría, específicamente en su idea, de cuño wittgensteiniano, de que no todos los conceptos significativos significan de la misma manera; en concreto, no todos los conceptos nombran o refieren objetos en, o propiedades de, una realidad extralingüística (T.1.1 p. 7).

El núcleo de The Nature of Truth lo constituye la exposición de la teoría prooracional ampliada de la verdad (en adelante teoría prooracional). Esta teoría tiene como centro la explicación que tradicionalmente han hecho las teorías prooracionales (Grover, Williams), complementado con observaciones acerca de las funciones sintácticas que cumple el predicado u operador de verdad dentro de los actos de habla por medio de los cuales adscribimos verdad a un contenido proposicional (i. e., las adscripciones de verdad) y acerca de las funciones pragmáticas que estos actos cumplen dentro de nuestras prácticas lingüísticas. La exposición de la teoría se desarrolla, así, en consonancia con la distinción clásica, atribuida a Peirce y Morris, entre sintaxis, semántica y pragmática. No obstante, dado el compromiso pragmatista subrayado atrás, esta distinción no compromete a la autora con una división ontológica «tripartita» de la realidad lingüística, o alguna excentricidad por el estilo. Por el contrario, esta división se hace con miras a explicar nuestras prácticas lingüísticas, en las cuales, ciertamente, estas tres funciones pueden evidenciarse de manera simultánea.

A juicio de Frápolli, la tarea fundamental de cualquier teoría de la verdad es explicar el funcionamiento del concepto de verdad, es decir, su significado. Para esto la autora propone analizar los aspectos sintácticos, semánticos y pragmáticos que muestran las expresiones típicas dentro de las cuales la verdad es puesta a trabajar, esto es, las expresiones por medio de las cuales cotidianamente adscribimos verdad a lo que alguien dice o cree: las adscripciones de verdad. Aquí es necesario puntualizar que el interés no se enfoca en la palabra «verdadero», en el significado de esta palabra, sino en el 
Verdad: Un análisis lógico-semántico

235

funcionamiento del concepto, el cual, como se verá más adelante puede aparecer gramaticalmente bajo diversas facetas.

Frápolli despliega su teoría evidenciando primero la función sintáctica del predicado u operador de verdad dentro de las adscripciones de verdad, luego muestra el rol semántico de estas adscripciones y, finalmente, presenta su función pragmática. El orden en que son tratadas las funciones, por decirlo así, de las adscripciones de verdad no expresa ninguna prioridad de alguna de ellas; la exposición de la teoría bien podría iniciar por el rol semántico o el pragmático. En últimas, ni la pragmática, ni la semántica ni la sintaxis son suficientes por sí solas para lograr una explicación de la verdad. Por motivos de espacio y claridad seguiré el orden presentado por la autora.

En primer lugar, la teoría sostiene que sintácticamente el predicado u operador de verdad cumple normalmente el papel de reestablecer el estatus de oración a expresiones singulares con contenido oracional. Así, para citar un ejemplo bastante usado en la bibliografía sobre la verdad, en

(1) La oración «el gato está sobre la alfombra» es verdadera

el rol del predicado de verdad es reestablecer la función sintáctica de oración a «el gato está sobre la alfombra». En (1) hay dos dispositivos lingüísticos: (a) unas comillas que convierten la expresión oracional en un término singular, es decir, que cumplen la función de nominalizar una expresión oracional, y (b) el predicado «es verdadera» que cumple la función de reestablecer el estatus de oración a la frase que está entrecomillada, esto es, cumple la función de denominalizar un término singular con contenido oracional. Esta misma función ocurre cuando la verdad no aparece como predicado, sino como operador más la partícula «que»:

(2) Es verdad que el gato está sobre la alfombra

En este caso, se tiene la partícula «que» que nominaliza la expresión oracional que le sigue y el operador «es verdad» que denominaliza la expresión. Esta función, que ha sido llamada por Horwich como denominalizadora, permite convertir las adscripciones de verdad en vehículos para afirmar contenidos proposicionales.

Lo anterior muestra que la discusión, mantenida entre otros por Puntel, acerca de si la verdad es un operador o un predicado no es adecuada para entender su funcionamiento dentro de nuestras prácticas lingüísticas, pues aunque el concepto aparezca gramaticalmente bajo algunas de estas dos 
formas, su función parece seguir siendo la misma. Ahora bien, la verdad puede aparecer gramaticalmente de otras maneras, como adjetivo:

(3) Victoria es una verdadera amiga,

también puede aparecer como adverbio:

(4) Ella es verdaderamente católica

(5) Ella verdaderamente dijo que su hermano se fue,

o incluso como nombre abstracto:

(6) Él dijo la verdad.

No en todas las ocasiones en que se usa la palabra verdad hay una adscripción de verdad en sentido estricto, pues no en todas las ocasiones se está adscribiendo verdad a un contenido proposicional. «Cualquier análisis de las adscripciones de verdad tiene que distinguir dos elementos, un contenido proposicional afirmado (o afirmable) y el acto de adscribir verdad explícitamente a este» (p. 38). En cualquier caso, «las diversas facetas que la noción de verdad puede asumir en una adscripción de verdad (como un adjetivo predicativo, un adjetivo atributivo, un adverbio y como un nombre) arrojan luces sobre los límites de un enfoque sintáctico sobre la verdad» (p. 38). Esto, por supuesto, no significa que las observaciones sintácticas sean fútiles; por el contrario, lo que ellas dejan ver es que la contribución de la verdad está en función de la aserción de contenidos proposicionales.

En segundo lugar, desde un punto de vista semántico, las adscripciones de verdad funcionan en nuestro lenguaje natural de manera similar a como funcionan las variables proposicionales en los lenguajes formales: pueden heredar y expresar cualquier contenido proposicional que haya sido afirmado en un acto asertivo exitoso. En este sentido, las adscripciones de verdad cumplen la función semántica de prooraciones, las cuales hacen parte de un conjunto más amplio de expresiones que pueden heredar diversos tipos de contenidos, las proformas. La clase de proformas más conocida, sin duda, son los pronombres que normalmente heredan un contenido singular (o nominal) o que adquieren contenido en actos referenciales directos. «Una clase particular de proforma puede ser clasificada atendiendo a su categoría en la gramática o atendiendo a su valor semántico (al estatus de su contenido)» (pp. 48-49). Aunque desde un punto de vista gramatical las proformas generalmente 
Verdad: Un análisis lógico-semántico

237

aparezcan como pronombres, desde un punto de vista lógico pueden corresponder a proadverbios, proadjetivos o prooraciones dependiendo de la clase de expresión de la cual hereden su contenido. Así, por ejemplo,

(7) Juan compró solo compró una camisa. Esa está bonita

(8) Te recomiendo ir allá. Esa ciudad es muy interesante.

(9) José es una persona muy ingeniosa. Esa es su mejor cualidad.

(10) Victoria dijo que los lunes son aburridos. Eso es verdad

En estos casos, de acuerdo con la clasificación gramatical tradicional hay un pronombre. Sin embargo, desde un punto de vista lógico, se pueden encontrar allí diversas clases de proformas: en (7) hay propiamente un pronombre (refiere a un término singular), en (8) un proadverbio (refiere a término adverbial), en (9) un proadjetivo (refiere a un término adjetival) y en (10) una prooración (refiere a una expresión oracional). Las proformas pueden ser simples o complejas. La expresión «esa» es simple, pero puede haber una expresión compleja que haga las veces de proforma, como en

(7a) La que él compró está bonita

Como se podrá observar, detrás de esta postura se encuentra la idea, presente en gran parte de la filosofía analítica, de que la gramática superficial de las expresiones, en este caso específico la del vocabulario de la verdad, esconde o desdibuja su función lógica. La discusión ya mencionada acerca de si la verdad es un predicado o un operador es un ejemplo palmario de este desdibujamiento. Por esto, es necesario realizar un análisis lógico-semántico de la verdad para ver cómo podemos explicar de una manera clara su funcionamiento lógico. En los siguientes ejemplos se evidencia que las adscripciones de verdad funcionan lógicamente como prooraciones complejas:

(11) La oración «el gato está sobre la alfombra» es verdadera

(12) A-José ha dicho que a Cristina le gusta cocinar B— Lo que José dijo es verdad

(13) La teoría de cuerdas es verdadera

(14) Todo lo que dice Alejandro es verdad. 
En estos casos se está adscribiendo verdad a (por lo menos) un contenido proposicional distinto. Sin embargo, (11)-(14) no funcionan de la misma manera, en ellos se despliegan las distintas funciones semánticas que cumplen las prooraciones dentro de los lenguajes naturales: (a) referencia directa, (b) referencia anafórica y (c) generalización. (11) Pertenece a la clase de adscripciones que Frápolli llama expositiva o exhibitiva (exbibitive), es decir, exhibe el contenido al cual se le está adscribiendo verdad. Esta clase de adscripciones ejemplifica la función de referencia directa que pueden ejecutar las proformas. Frápolli muestra por qué la mayor parte de análisis lógicosemánticos de la verdad en el siglo XX llegan a conclusiones similares como «el ascenso semántico» de Quine, la «función denominalizadora» de Horwich, la «función descitacional (disquitational)» de Field, entre otras ${ }^{2}$. La mayor parte de estos análisis se han concentrado específicamente en las adscripciones expositivas y han concluido que no hay nada más que decir con respecto a la verdad que lo que es implicado por la convención- $V$, lo cual los ha conducido a fijarse exclusivamente en las funciones sintácticas de la verdad, explicación que, como observamos unas páginas atrás, es insuficiente. En (12) aparece una adscripción de verdad ciega en la que no se exhibe el contenido afirmado y por tanto su funcionamiento no queda totalmente explicado por un análisis de (11). En (12) la adscripción de verdad adquiere su contenido de manera anafórica de un acto de habla previo. En (13) y (14), por otro lado, se observa que las adscripciones de verdad, exhibitivas o ciegas, sirven como dispositivos de generalización.

Es necesario prestar atención a la distinción contemporánea entre contenido y significado lingüístico con miras a observar que las adscripciones de verdad no tienen contenido por sí solas, pero esto no significa que sean ambiguas o carentes de significado. La distinción entre el nivel del contenido — de lo que se dice- y el nivel del significado de los constituyentes lingüísticos permite evidenciar que no hay ninguna ambigüedad en el

\footnotetext{
2 Todas estas teorías han sido tradicionalmente rotuladas bajo el nombre de deflacionismo. Frápolli muestra la inconveniencia de esta etiqueta por cuanto, por un lado, "es un término usado metafóricamente y no hay una definición común adoptada por proponentes y detractores" y, por otro, "el término tiene un aire $(\operatorname{scent})$ peyorativo que sugiere que la teoría así caracterizada ha sido desprovista de algunos aspectos que una teoría de la verdad debe contener" (p. 11).

por un lado, no hay un acuerdo con respecto a lo que realmente es el deflacionismo y, por el otro, este término siempre parece venir acompañado de una
}

Análisis. Revista de investigación filosófica, vol. 2, n. 1 (2015): 233-244 
Verdad: Un análisis lógico-semántico

239

aprendizaje ni en el uso de una oración como «lo que José dijo es verdad»; el fenómeno que hay que entender es que por medio de esta oración se pueden decir cosas distintas. Así, por ejemplo, si José dijo que los lunes son aburridos, la oración en cuestión expresará «los lunes son aburridos», pero si dijo «a Cristina le gusta cocinar», con la oración en cuestión se expresará esto y no otra cosa. Las adscripciones de verdad pueden heredar cualquier contenido proposicional aunque su funcionamiento lógico es el mismo.

En tercer lugar, las adscripciones de verdad tienen la función pragmática de hacer explícitos los compromisos adquiridos a la hora de afirmar un contenido. Cuando un hablante atribuye verdad a un contenido está (a) mostrando que puede ser usado como premisa en futuros juegos inferenciales ${ }^{3}$ y (b) exhibiendo nuestro compromiso para dar razones que apoyen este contenido. Se configura entonces un significado expresivo de la verdad de acuerdo con el cual esta no modifica o contribuye con el contenido de la proposición a la cual es adscrita, sino que permite evidenciar ciertos compromisos propios de la aserción. «Si una adscripción de verdad y el acto asertivo al cual ella refiere comparten su contenido proposicional, el rol de la verdad no puede ser descriptivo, de otra manera, esto se vería reflejado en la proposición expresada» (p. 74). Esto permite desterrar cualquier intento de teoría sustantivista de la verdad. Así, contrario a lo que una primera lectura del título del libro puede sugerir, la verdad por sí misma no tiene ninguna naturaleza.

La reflexión que hace Frápolli respecto de la función pragmática de la verdad permite notar que la adscripción de verdad ocurre una vez los contenidos ya han sido aceptados, es decir, una vez los contenidos ya tienen el estatus epistémico de conocimiento o, por lo menos, de creencia aceptada. Estrictamente hablando las adscripciones de verdad no tienen ninguna función epistémica, no producen ni causan el estatus epistémico de conocimiento aceptado. Observemos los siguientes ejemplos,

(15) Colombia es un país tropical

(16) Es verdad que Colombia es un país tropical.

En estos dos casos ciertamente no hay diferencia semántica, el contenido expresado en (15) es exactamente el mismo que el expresado en (16). El

\footnotetext{
${ }^{3}$ De acuerdo con la distinción debida a Cohen de la epistemología contemporánea entre creer y aceptar, las adscripciones de verdad muestran que el hablante no solo cree sino que además acepta el contenido afirmado.
} 
operador «es verdad que» presente en (16) tampoco aporta diferencia epistemológica alguna. Una vez el contenido proposicional ha sido aceptado, una vez ha pasado nuestros filtros epistemológicos, podemos adscribir verdad sin que la adscripción por sí misma le otorgue un grado epistémico superior o algo por el estilo.

La teoría prooracional esbozada hasta aquí conlleva los primeros cuatro capítulos del libro. En ellos Frápolli no solo argumenta detalladamente su teoría, sino que además discute posiciones contemporáneas distintas respecto de la verdad y muestra cómo los principales hallazgos de estas pueden explicados satisfactoriamente por la teoría prooracional. Las intuiciones desarrolladas por filósofos como Wittgenstein, Russell, Ramsey, Quine, Strawson, Williams entre otros con respecto a la verdad tienen cabida dentro de la teoría de Frápolli. Al tiempo, Frápolli muestra cómo su concepción del significado de la verdad es consecuente con los hallazgos de las posiciones más importantes de la filosofía del lenguaje contemporánea.

Como ya se ha dicho, Frápolli presenta una explicación acerca del funcionamiento de las adscripciones de verdad dentro del lenguaje natural. Ciertamente en muchos momentos usamos el predicado u operador de verdad para adscribir verdad a contenidos proposicionales evidenciando con ello nuestros compromisos con tales contenidos. Este, puede ser llamado, a riesgo de cometer alguna imprecisión, un uso literal o convencional de la verdad. Sin embargo, parece que hay otros usos, donde la verdad no tiene tal carácter atributivo, sino que se usa para expresar «sinceridad», «veracidad», «realidad» o cosas por el estilo. Estos últimos pueden ser denominados como usos metafóricos de la verdad. Con esta distinción en mente, parece claro que la teoría expuesta por Frápolli da cuenta de los usos literales, pero no es tan claro si da cuenta de lo que aquí se ha llamado usos metafóricos. ${ }^{4}$ Observemos los siguientes ejemplos:

(17) De verdad quiero cambiar

(18) Ese es un pato de verdad

(19) Aristóteles es un filósofo de verdad

\footnotetext{
${ }^{4}$ Este cuestionamiento me fue sugerido en primera instancia por el profesor Miguel Ángel Pérez Jiménez. No estoy seguro de haberlo plasmado correctamente, en cualquier caso, cualquier imprecisión en la formulación es responsabilidad mía.
} 
Verdad: Un análisis lógico-semántico

241

Sobre este asunto el defensor de la teoría prooracional podría decir dos cosas. Por un lado, la teoría está comprometida con la explicación del concepto de verdad, no de la palabra «verdad»; es decir, no pretende explicar todos los usos de la palabra «verdad» o «verdadero». En este caso, el teórico prooracional estaría reconociendo que su teoría solo da cuenta de los usos literales. Por otro lado, el teórico prooracional podría afirmar que en estos casos ciertamente la verdad no cumple la función sintáctica de denominalizador, pero la idea de que la verdad tiene un significado expresivo, uno que no contribuye al contenido afirmado se sigue manteniendo. La diferencia estaría en el tipo de compromisos que el hablante adquiere cuando usa «verdad» en alguno de estos sentidos metafóricos. A primera vista, estos no podrían ser compromisos inferenciales, o por lo menos no del mismo tipo que en (16). Esto, por supuesto, es apenas un intento de dilucidar por dónde podría ir la respuesta del teórico prooracional, explorar cada una de estas vías sobrepasa las intenciones de este texto.

Ahora bien, es una opinión generalizada que la teoría prooracional es en el fondo una teoría redundantista de la verdad, es decir, sostiene que la verdad no cumple ningún rol y que lo que puede ser expresado con la verdad puede ser expresado también sin ella. De acuerdo con Frápolli es necesario precisar de qué tipo de redundancia se está hablando. Para ella, tanto los defensores como los opositores de la redundancia tienen en mente alguna de estas dos nociones: (a) redundancia de contenido: una expresión es redundante respecto a su contenido si, y solo si, no modifica la proposición expresada por las oraciones en las cuales la expresión aparezca (b) redundancia de fuerza: una expresión es redundante respecto a la fuerza si, y solo si, la fuerza del acto de habla no varía como una consecuencia de la inclusión o exclusión de la expresión (p. 114). La tesis expresivista sostiene que la verdad no modifica la proposición expresada, aunque, como se vio, de aquí no se sigue que la verdad no cumpla ningún papel. Pasar de (a) a la idea de que la verdad no cumple ningún rol dentro del lenguaje no es más que regresar a la anticuada (y equivocada) reducción del lenguaje natural al lenguaje descriptivo, reducción contra la que Austin ya nos había prevenido (falacia descriptivista). Lo mismo parece ocurrir con (b). Pragmáticamente la verdad es un marcador de fuerza ilocucionaria, es decir, no modifica la fuerza del acto de habla al cual se adscribe; sin embargo, de allí no se sigue que la verdad no cumpla ningún papel. 
«La verdad, las expresiones de verdad y las adscripciones de verdad contribuyen a la comunicación humana en diferentes niveles. Las expresiones de verdad ejecutan la tarea sintáctica de desplegar términos singulares con un contenido proposicional completo en oraciones completas. Las adscripciones de verdad son las contrapartes en el lenguaje natural de las variables en los lenguajes artificiales. Los hablantes usan las adscripciones de verdad para aprobar (endorse) contenidos singulares o como medios para afirmar contenidos generales» (p. 116).

El rol que cumple la verdad y las adscripciones de verdad dentro del lenguaje natural, como se ve, es altamente complejo, para nada superfluo. El aparato de la verdad cumple un papel expresivo en el lenguaje natural, papel que no le es exclusivo, pues también lo pueden cumplir los pronombres u otras prooraciones complejas, pero que, de todas maneras, no es nada desdeñable. El análisis lógico-semántico de la verdad muestra que esta es una noción que no tiene características especiales o misteriosas (como lo han hecho creer recientemente aquellos que creen que la verdad es indefinible), pero que tampoco es prescindible (como lo han hecho creer los defensores de la teoría de la redundancia y algunos minimalistas).

En el libro se puede hallar una interesante (di)solución prooracional a la paradoja del mentiroso (cap. 5), así como también una discusión detenida de objeciones clásicas a la teoría prooracional de índole lógico, semántico y epistemológico (cap. 7). Por cuestiones de espacio no me referiré a lo sostenido en estos capítulos, sino que terminaré con algunas observaciones generales acerca de la teoría de Frápolli.

Dos pretensiones generales pueden ser rastreadas en la teoría de Frápolli: neutralidad y exhaustividad. Con respecto a la primera, la filósofa española sostiene que no es necesario tomar partido por alguna de las posiciones contemporáneas ya sea en epistemología (p. 139), en metafísica (p. 139) o en filosofía del lenguaje (p. 7). En la medida en que la verdad no es un concepto ni epistemológico ni metafísico, parece que la neutralidad en estos dos campos es razonable. Efectivamente, la teoría prooracional no se compromete con un realismo (o anti-realismo) ya sea epistemológico o metafísico; en últimas, una teoría de la verdad tiene que dar cuenta del significado de la verdad para lo cual no necesita comprometerse ni con cuál es la estructura del mundo ni con cuál es nuestra manera de acceder epistémicamente a él. La deseada neutralidad en filosofía del lenguaje, sin embargo, es un poco más difícil de mantener. De acuerdo con la propia Frápolli, para sostener una teoría de la verdad «no es necesario tener una determinada posición teórica acerca de los debates en la 
Verdad: Un análisis lógico-semántico

243

filosofía del lenguaje del siglo $\mathrm{XX}$, aunque es necesario poseer una comprensión general acerca de cómo trabaja el lenguaje de acuerdo con las teorías contemporáneas del significado y el contenido»(p. 7). No obstante, parece ser que a lo largo del libro se terminan favoreciendo unas teorías contemporáneas, en lugar de otras. Así, por ejemplo, la elección de la explicación del significado en términos de la distinción significado lingüístico/contenido, la llamada teoría del doble factor (double factor theory of meaning p. 58), combinada con la actitud pragmática de Frápolli enunciada al inicio de este comentario, parece que nos obliga a tomar una posición en el debate contemporáneo entre minimalistas (o semanticistas) y contextualistas. Otro tanto parece ocurrir con la idea de que los factores contextuales inciden en la determinación del contenido.

Tal vez Frápolli sea consciente de estas tensiones y, por esta razón, cuando se refiere a la pretendida neutralidad en filosofía del lenguaje siempre agregue la expresión «tanto como sea posible». Empero, si la intención del libro, como lo sugiere el subtítulo, es dar cuenta del significado de las adscripciones de verdad, tal vez sea deseable tomar una posición en todos estos debates de la filosofía contemporánea acerca de qué es el significado y cómo se determina.

Con respecto a la segunda pretensión, la teoría prooracional, al parecer, pretende ser exhaustiva: intenta dar cuenta de todos aquellos casos en los cuales el concepto de verdad es puesto a trabajar. Esto puede interpretarse de dos maneras distintas, y no por ello inconexas: por un lado, que pretende explicar las adscripciones de verdad a proposiciones matemáticas, éticas, científicas, etc., y, por otro, que procura explicar todos los usos de las expresiones de verdad. Sobre lo primero, en efecto, la adscripción de verdad funciona de la misma manera sin importar el tipo de contenido que esté heredando. Así, por ejemplo en

(20) Es verdad que el único primo par es 2, y

(21) Es verdad que las mujeres tienen los mismos derechos que los hombres

la adscripción de verdad está funcionando lógico-semánticamente de la misma manera. La diferencia se ubicaría en el tipo de razones que uno estaría comprometido a dar para defender cada uno de los contenidos; sin embargo, esto último ya es ajeno al funcionamiento de la verdad misma. Sobre lo segundo, como se observó, aún hace falta precisar si la teoría prooracional 
permite explicar lo que aquí, vagamente, se ha denominado usos metafóricos de la verdad. Sospecho que el compromiso de exhaustividad, si es que hay tal, adquirido por Frápolli corresponde solo a la primera interpretación.

En definitiva, The Nature of Truth es un libro fascinante de obligada lectura para todos aquellos interesados en la filosofía del lenguaje contemporánea en general y en las teorías de la verdad en particular. Por mi parte, me he ido convenciendo de que la teoría prooracional es la mejor explicación que tenemos en el momento acerca de cómo funciona el concepto de verdad dentro de nuestros lenguaje naturales. 